\title{
Hybrid Multi-Attribute Decision Making Methods: An Application
}

\author{
Yonghong MA, Xin SU, Yue ZHAO
}

\begin{abstract}
The location selection of warehouses is considered to be a strategic decision for logistics enterprises in improving the quality of logistic services. In order to improve the science and accuracy of enterprise warehouse location decisions, in terms of hybrid multi-attribute decision-making problems and decision-maker expectations, this paper proposes an analytical method for site selection decisions of logistics enterprise warehousing centres based on the cumulative prospect theory. The research results demonstrate that the decision matrix with three information types, namely clear number, interval number and language phrase is transformed into a decision matrix with a consistent measure effect, which improves the accuracy of attribute representation. Moreover, the factors influencing the decision-making of warehouse locations with different attributes are endowed with subjective expectations, which can better adapt to the different needs and preferences of decision-makers. The results indicate that strategic ranking of decision-making schemes can be obtained by introducing a cumulative foreground theory to establish the value matrix relative to the reference point as well as calculating the comprehensive foreground value of each scheme. The effectiveness of this analytical method is proven with the use of certain feasible and effective examples.
\end{abstract}

Keywords: Multi-attribute decision-making; Cumulative prospect theory; Site selection of warehousing centres; Logistics enterprise

\section{INTRODUCTION}

The site selection and layout of logistics enterprises play a decisive role in achieving economies of scale and service superiority [1], and aid in solving the problem of supply chain coordination under asymmetric information [2]. At present, numerous domestic and global modelling methods are applied to solve problems arising from the site selection of logistic enterprises. Several models are extensively used, and they contribute significantly to the site selection of logistics enterprises. A few models, such as the centroid method, are more frequently used than others. This method is derived from analytic geometry functions and is used as a continuous location model for single-target locations. The basic principle takes the demand point and logistics centre in the logistics network as a point on a certain plane. Taking the quantity of demand or resources as the point between the quantities of transport, this point on the plane will therefore be the most optimal location for a logistics centre. This approach is referred to as the centroid method and uses the transport cost as the only factor for the selection of location. The aims of this site selection process are to minimise the total transport costs [3], and effectively calculate a theoretically optimal result in a simple and quick manner. However, owing to the fact that logistic distribution networks cannot always satisfy the model design, transportation costs may vary depending on multiple factors (such as fixed investment and facility operation costs), and the coordinates of the calculated optimal solution may change accordingly [4]. The covering location model assumes that all demand points of the logistics distribution are covered, with the aim of ensuring the lowest number of supply points constructed within a covering area or a minimum construction cost. This approach serves as an integer programming model based on the set covering problem, provided that the construction cost of supply points is fixed [5]. For the min-max problem (also referred to as the "pcentre problem"), on the condition that $p$ supply points are selected within the logistics distribution coverage, the target solution is to ensure that the sum of the distances from all logistics demand points to the supply points is the lowest [6]. Moreover, it can also be regarded as a bulk port scheduling problem aimed at minimizing the total service time and makespan [7]. The Baumol-Wolfe model generally considers transport with variable and fixed costs in the location problem of logistics warehousing centre [8]. Its aim is to minimise transportation costs, which are applicable to the network optimization problem with multiple supply and demand points. However, the initially assumed value in the model will more than likely lead to a non-optimal solution [9]. The 0-1 integer programming model is one of the most widely and frequently used methods for the site selection of logistics warehousing centres. It serves as a modified non-linear programming model based on the Baumol-Wolfe model, and intends to solve the sum of transport, fixed, operating and other costs incurred by the warehousing centre using the heuristic algorithm. Its target solution is to minimise the total cost [10]. The genetic algorithm is a calculation method that simulates the natural selection and biological evolution process of the evolution theory, and provides a robust optimisation technique that can effectively solve combinational optimisation problems. During the site selection of logistics warehousing centres, it can solve the optimal solution to minimise the sum of transport, fixed and variable costs [11]. All the methods mentioned above that aid in site selection of logistics warehousing centres, offer their own advantages and disadvantages. Overall, the vast majority of location methods intend to minimise the total cost from sub-costs (transport, fixed, variable and operating) perspective to obtain the optimal coordinates for the warehousing centre. However, the actual decision process for the site selection of logistics warehousing centres must consider multiple factors, such as geographical transportation, public infrastructure and human capital, which have varying attribute values. Therefore, this paper classifies the site selection of logistics warehousing centres into the selection problem of limited schemes with multiple attributes, also known as the multiattribute decision-making method.

The multi-attribute decision-making problem provides an extensive, realistic context during the site selection process of logistics warehousing centres. The decision- 
maker may hold certain expectations for individual attributes, for example, price, area, and other warehousing centre attributes, when selecting location schemes [12]. Therefore, it is of academic research value and realistic significance to examine the manner in which to solve the multi-attribute decision-making problem with decisionmaker expectations. Current research on the multi-attribute decision-making problem has captured the attention of several scholars, but few targeted decision-making analytic methods exist. From the literature available it can be seen that scholars have carried out their work from two perspectives. The first perspective is based on the expected utility theory, which assumes that the decision-maker should be of complete rationality. A research study [13], proposed an interactive decision-making method based on expectation levels, while another [14], combined generalised data envelopment analysis with the genetic algorithm, and then selected an option from the Pareto optimality solutions that was closest to the decisionmaker's expected scheme, Moreover, an interactive decision-making method [15] based on the stochastic dominance and expectation level was proposed, which applied the stochastic dominance criteria to judge the stochastic dominance relationship between every two schemes, and obtained the optimal scheme by interactively adjusting the decision-maker's expectation levels on the attribute values. The second perspective considers the decision-maker's behaviour to be bounded by rationality [16], i.e., it assumes that the decision-maker does not always seek the highest utility, but rather selects the scheme to his or her highest satisfaction. The question then arises as to how to introduce the decision-maker's psychological behaviour into the multi-attribute decisionmaking analysis and select the optimal scheme. For the multi-attribute decision-making problem where the attribute weight is not completely determined and the attribute value of the scheme is a trapeziform fuzzy number one study [17] successfully ranked the order of schemes according to the prospect value function of the trapeziform fuzzy number, as defined by the cumulative prospect theory. This was achieved by using the ideal scheme as a reference point and establishing a nonlinear programming model that maximises the comprehensive prospect value of individual schemes. For the risk-based decision-making problem, a multi-attribute decision-making method was proposed based on linguistic assessment and the cumulative prospect theory. This method calculates the prospect value for individual schemes by transforming the linguistic assessment information into an integer number and then ranks the order of the schemes according to the cumulative prospect theory [18]. Such methods provide a solid foundation in accounting for the decision-maker's expectations in multi-attribute decision-making problems. However, in practice, the types of expectations and attribute values often involve a clear number, interval number and language phase time, such as the hybrid multiattribute decision-making problem and the decision-maker expectations [19]. Of these attributes, the expectation and attribute values regarding 'accuracy' and 'price' are expressed in the form of a clear or an interval number, while 'reliability' and 'maintainability' are often difficult to quantify, and their expectation and attribute values are generally expressed in the form of a language phrase.
Therefore, it is of practical significance to examine the hybrid multi-attribute decision-making problem with the decision-maker's expectations in order to select an optimal site for a logistics enterprise warehousing centre. To this end, this paper proposes an analytical analysis method for a location on the location, based on the cumulative prospect theory [20]. This method transforms the decision matrix according to the expectation (reference point) of various attribute types provided by the decision-maker of warehousing centre locations. Considerations are made according to the different decision-maker attitudes and risks in income and loss, as well as the subjective selections of the importance of individual attributes. A calculation of the comprehensive prospect value of each scheme is carried out, which ranks all schemes according to their comprehensive prospect value size.

\section{PROBLEM DESCRIPTION}

A hybrid multi-attribute decision-making problem with decision-maker expectations, $P=\left\{P_{1}, P_{2}, \ldots, P_{m}\right\}$, is denoted as a set of $m$ alternatives, where $P_{i}$ is the $i^{\text {th }}$ alternative. $A=\left\{A_{1}, A_{2}, \ldots, A_{n}\right\}$ is the set of $n$ attributes, where $A_{j}$ is the $j^{\text {th }}$ attribute and $A_{1}, A_{2}, \ldots, A_{n}$ are additively independent. $w=\left(w_{1}, w_{2}, \ldots, w_{n}\right)$ is the attribute weight vector, where $w_{j}$ is the weight or degree of importance of attribute $A_{j}$, which satisfies $w_{j} \geq 0 . \sum_{j=1}^{n} w_{j}=1 ; E=\left(e_{1}, e_{2}\right.$, $\left.\ldots, e_{n}\right)$ is the expectation vector of the attribute given by the decision-maker, according to existing information and future expectations, where $e_{j}$ is the decision-maker's expectation of the attribute $A_{j} . \boldsymbol{D}=\left[d_{i j}\right]_{m \times n}$ is the decision matrix, where $d_{i j}$ is the attribute or evaluation value of the scheme $P_{i}$ with respect to attribute $A_{j}$. In this paper, given the presence of three types (clear number, interval number and language phrase) of expectations and attribute values, the expectation and attribute value for the same attribute are expressed in the same information form. For the sake of convenience, we denote $Z=\{1,2, \ldots, z\}, A^{C}, A^{I}, A^{P}$, where the subset of attributes, decision-maker's expectations or attribute values are expressed in the form of a clear number, interval number or language phrase respectively: $A^{C}=\left\{A_{1}, A_{2}, \ldots, A_{r 1}\right\}, A^{I}=\left\{A_{r 1+1}, A_{r 1+2}, \ldots\right.$, $\left.A_{r 2}\right\}, A^{P}=\left\{A_{r 2+1}, A_{r 2+2}, \ldots, A_{n}\right\}, A^{C} \cup A^{I} \cup A^{P}=A$; We denote $T=\{1,2, \ldots, n\}, S_{1}, S_{2}, S_{3}$ as the set of subscripts for the subset of attributes $A^{C}, A^{I}, A^{P}, S_{1}=\left\{1,2, \ldots, r_{1}\right\}, S_{2}=$ $\left\{r_{1}+1, r_{1}+2, \ldots, r_{2}\right\}, S_{3}=\left\{r_{2}+1, r_{2}+2, \ldots, r\right\}$, $S_{1} \cup S_{2} \cup S_{3}=T$. For the decision-maker's expectation and attribute value, the detailed description is provided as follows:

(1) When the attribute $A_{j} \in A^{C}, e_{j}=e_{j}^{\prime}, d_{i j}=d_{i j}^{\prime}$, $j \in S_{1}, i \in Z$. Here, $e_{j}^{\prime}$ and $d_{i j}^{\prime}$ are real numbers without loss of generality, and it is assumed that $e_{j}^{\prime} \geq 0, d_{i j}^{\prime} \geq 0$.

(2) When the attribute $A_{j} \in A^{I}$, then $e_{j}=e_{j}^{\prime \prime}$, $d_{i j}=d_{i j}^{\prime \prime}, j \in S_{2}, i \in Z$. Here, $e_{j}^{\prime \prime}$ and $d_{i j}^{\prime \prime}$ are interval numbers, $e_{j}^{\prime \prime}=\left[e_{j}^{L L}, e_{j}^{U L}\right], d_{i j}^{\prime \prime}=\left[d_{i j}^{L L}, d_{i j}^{U L}\right]$, without loss of 
generality, and it is assumed that $e_{j}^{U L} \geq e_{j}^{L L} \geq 0$, $d_{i j}^{U L} \geq d_{i j}^{L L} \geq 0$.

(3) When the attribute $A_{j} \in A^{P}, e_{j}=e_{j}^{\prime \prime \prime}, d_{i j}=d_{i j}^{\prime \prime \prime}$, $j \in S_{3}, i \in Z$. Here, $e_{j}^{\prime \prime \prime}$ and $d_{i j}^{\prime \prime \prime}$ are language phrases, $e_{j}^{\prime \prime \prime}, d_{i j}^{\prime \prime \prime} \in L$. Moreover, $L$ is the predefined set of language phrases, namely $L=\left\{l_{g} \mid g=0,1, \cdots, \frac{R}{2}-1, \frac{R}{2}, \frac{R}{2}+1, \cdots, R\right\}$, where $l_{g}$ is the $(g+1)^{\text {th }}$ language phrase in $L, R$ is generally an even number and $\mathrm{R}+1$ is the number of elements in the set $L$. For example, if $R=6$, then $L=\left\{l_{0}, l_{1}, l_{2}, l_{3}, l_{4}, l_{5}, l_{6}\right\}=\{V P, P, M P, M, M G, G, V G\}$.

$L$ exhibits the following characteristics:

(1) Rearranged as: when $g \geq k$, then $l_{g} \succ l_{k}$, the symbol ' $\succ$ ' means 'better than or equal to'.

(2) Inverse operator 'inv': when $k=R-g$, $\operatorname{inv}\left(l_{g}\right)=l_{k}$.

(3) Maximisation and minimisation operations: when $l_{g} \succ l_{k}, \max \left\{l_{g}, l_{k}\right\}=l_{g}, \quad \min \left\{l_{g}, l_{k}\right\}=l_{k}$.

In this paper, for the convenience of processing and calculating language phrases, we consider transforming language phrases into the corresponding triangular fuzzy number. If $e_{j}^{\prime \prime \prime}$ and $d_{i j}^{\prime \prime \prime}$ are language phrases $l_{g}$ in the language phrase set $L$, the calculation formula for transforming this into the triangular fuzzy number $\mu^{t f n}$ will be:

$\mu^{t f n}=\left(\mu^{1}, \mu^{2}, \mu^{3}\right)=\left[\max \left(\frac{g-1}{R}, 0\right), \frac{g}{R}, \min \left(\frac{g+1}{R}, 1\right)\right]$

Furthermore, with respect to the hybrid multi-attribute decision-making programme, attributes can be classified into benefit attribute and cost attributes. Greater benefit and smaller cost attributes will be superior. We denote $E_{p}$, $E_{c}$ as the set of subscripts for the benefit and cost attribute, respectively, to satisfy: $E_{p} \cup E_{c}=T, E_{p} \cap E_{c}=\varnothing$. The problem to be solved in this case is how to rank the order of all schemes using an analytical decision-making method, according to the decision-maker's expectation vector $\boldsymbol{E}$, attribute weight vector $\boldsymbol{W}$, and the decision matrix $\boldsymbol{D}$.

\section{RESEARCH METHOD}

In order to solve the problem, described in Section 2, the study proposes a decision-making method based on the cumulative prospect theory.

Firstly, the reference point for individual attributes is selected. Because the decision-maker's target can be used as the reference point and this target inherits various characteristics of the cumulative prospect theory, the expectation on individual attributes can be treated as the target [21]. As a result, this study uses the decision-maker's expectation on individual attributes $q_{j}$ as the reference point corresponding to each attribute.

Secondly, the information is organised and normalised in order to eliminate the impact of different physical dimensions on the resulting decision. Therefore, it is necessary to normalise the expectation or reference point vector $E=\left(e_{1}, e_{2}, \cdots, e_{n}\right)$ to $N=\left(n_{1}, n_{2}, \cdots, n_{n}\right)$, and normalise the decision matrix $\boldsymbol{D}=\left[d_{i j}\right]_{m \times n}$ to the matrix $\boldsymbol{Y}=$ $\left[y_{i j}\right]_{m \times n}$. The specific normalised calculation formulae are expressed as follows:

(1) When the attribute $A_{j} \in A^{C}$, the normalised calculation formula is

$\tilde{n}_{j}=\left\{\begin{array}{l}\frac{e_{j}^{\prime}-d_{j}^{\prime \prime}}{\overrightarrow{d_{j}}-\overleftarrow{d_{j}}}, j \in S_{1} \cap E_{p} \\ \frac{\overrightarrow{d_{j}}-e_{j}^{\prime}}{\overrightarrow{d_{j}}-\widetilde{d_{j}}}, j \in S_{1} \cap E_{c}\end{array}\right.$

$\tilde{y}_{i j}=\left\{\begin{array}{l}\frac{d_{i j}^{\prime}-\overleftarrow{d_{j}}}{\overrightarrow{d_{j}}-\overleftarrow{d_{j}}}, i \in Z, j \in S_{1} \cap E_{p} \\ \frac{\overrightarrow{d_{j}}-d_{i j}^{\prime}}{\overrightarrow{d_{j}}-\overleftarrow{d_{j}}}, i \in Z, j \in S_{1} \cap E_{c}\end{array}\right.$

where $\tilde{n}_{j}$ is denoted as the normalised reference point vector of the clear number and $\tilde{y}_{i j}$ is denoted as the normalised decision matrix of clear number. Here,

$\overrightarrow{d_{j}}=\max \left[\max _{1 \leq i \leq m}\left(d_{i j}^{\prime}\right), e_{j}^{\prime}\right], j \in S_{1}$
$\overleftarrow{d_{j}}=\min \left[\min _{1 \leq i \leq m}\left(d_{i j}^{\prime}\right), e_{j}^{\prime}\right], j \in S_{1}$

(2) When the attribute $C_{j} \in C^{I}$, the normalised calculation formula is:

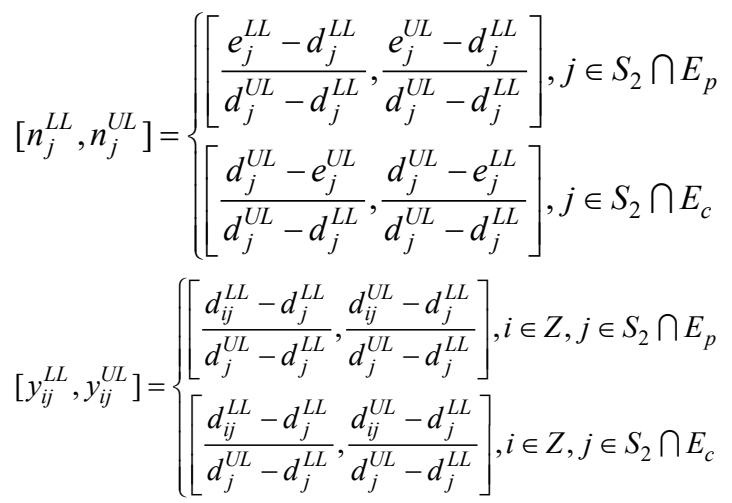

where $\left[n_{j}^{L L}, n_{j}^{U L}\right]$ is denoted as the normalised reference point vector of the interval number and $\left[y_{i j}^{L L}, y_{i j}^{U L}\right]$ is denoted as the normalised decision matrix of the interval number. Here,

$$
\begin{aligned}
& d_{j}^{U L}=\max \left[\max _{1 \leq i \leq m}\left(d_{i j}^{U L}\right), e_{j}^{L L}\right], j \in S_{2} \\
& d_{j}^{L L}=\min \left[\min _{1 \leq i \leq m}\left(d_{i j}^{L L}\right), e_{j}^{L L}\right], j \in S_{2}
\end{aligned}
$$


(3) When the attribute $A_{j} \in A^{P}$, the normalised calculation formula is:

$$
\begin{aligned}
& \dot{n}_{j}= \begin{cases}\dot{e}_{j}, & j \in S_{3} \cap E_{p} \\
\operatorname{inv}\left(\dot{e}_{j}\right), & j \in S_{3} \cap E_{c}\end{cases} \\
& \dot{y}_{i j}= \begin{cases}\dot{d}_{i j}, & i \in Z, j \in S_{3} \cap E_{p} \\
\operatorname{inv}\left(\dot{d}_{i j}\right), & i \in Z, j \in S_{3} \cap E_{c}\end{cases}
\end{aligned}
$$

where $\dot{n}_{j}$ is denoted as the normalised reference point vector of the language phrase and $\dot{y}_{i j}$ is denoted as the normalised decision matrix of the language phrase.

With reference to Eq. (1), the language phrase $\dot{n}_{j}, \dot{y}_{i j}$ can be transformed into the corresponding triangular fuzzy number sum $n_{j}^{t f n}$ and $y_{i j}^{t f n}$, respectively, i.e. $n_{j}^{t f n}=\left(n_{j}^{1}, n_{j}^{2}, n_{j}^{3}\right), \quad y_{i j}^{t f n}=\left(y_{i j}^{1}, y_{i j}^{2}, y_{i j}^{3}\right)$. Thereafter, the income or loss of the attribute value of the individual attributes of each scheme relative to the reference point is calculated. In this case, the attribute value and reference point are first compared, in order to identify the size relationship between the attribute value $y_{i j}$ and reference value $n_{j}$, and the specific comparison method is described as follows:

(1) When the attribute $A_{j} \in A^{C}$, the size relationship between the attribute value $\tilde{y}_{i j}$ and reference point $\tilde{n}_{j}$ can be compared directly.

(2) When the attribute $A_{j} \in A^{I}$, denote

$$
\begin{aligned}
& t\left(y_{i j}^{\prime \prime}\right)=\frac{d_{i j}^{L L}+d_{i j}^{U L}}{2}, i \in Z, j \in S_{2} \\
& t\left(n_{j}^{\prime \prime}\right)=\frac{n_{j}^{L L}+n_{j}^{U L}}{2}, j \in S_{2} \\
& x\left(y_{i j}^{\prime \prime}\right)=\left(d_{i j}^{U L}-d_{i j}^{L L}\right), i \in Z, j \in S_{2} \\
& x\left(n_{j}^{\prime \prime}\right)=\left(n_{j}^{U L}-n_{j}^{L L}\right), j \in S_{2}
\end{aligned}
$$

When $t\left(y_{i j}^{\prime \prime}\right) \neq t\left(n_{j}^{\prime \prime}\right)$, the attribute value $y_{t}^{\prime \prime}$ and reference point $n_{j}^{\prime \prime}$ will be compared in the following manner [22]: (a) if $t\left(y_{i j}^{\prime \prime}\right)>t\left(n_{j}^{\prime \prime}\right)$, then $y_{i j}^{\prime \prime}>n_{j}^{\prime \prime}$; (b) if $t\left(y_{i j}^{\prime \prime}\right)<t\left(n_{j}^{\prime \prime}\right)$, then $y_{i j}^{\prime \prime}<n_{j}^{\prime \prime}$. When $t\left(y_{i j}^{\prime \prime}\right)=t\left(n_{j}^{\prime \prime}\right)$, the attribute value $y_{t}^{\prime \prime}$ and the reference point $n_{j}^{\prime \prime}$ will be compared as follows: (a) if $x\left(y_{i j}^{\prime \prime}\right)<x\left(n_{j}^{\prime \prime}\right), y_{i j}^{\prime \prime}>n_{j}^{\prime \prime}$; (b) if $x\left(y_{i j}^{\prime \prime}\right)=x\left(n_{j}^{\prime \prime}\right), y_{i j}^{\prime \prime}=n_{j}^{\prime \prime} ;$ (c) if $x\left(y_{i j}^{\prime \prime}\right)>x\left(n_{j}^{\prime \prime}\right), y_{i j}^{\prime \prime}<n_{j}^{\prime \prime}$.

(3) When the attribute $A_{j} \in A^{P}$, set the language phrase corresponding to the attribute value $y_{i j}^{t f n}$ as $L_{g}(g=0$, $1,2, \ldots, R)$, the reference point $n_{j}^{t f n}$ as $L_{g}(g=0,1,2, \ldots$, $R), L_{k}(k=0,1, \ldots, R)$ respectively, and the comparison method is described as follows: (a) if $L_{g} \succ L_{k}, y_{i j}^{t f h}>n_{j}^{t f n}$; (b) if $L_{g}=L_{k}, y_{i j}^{t f n}=n_{j}^{t f n}$; (c) if $L_{g} \prec L_{k}, y_{i j}^{t f n}<n_{j}^{t f n}$. Furthermore, the distance between the attribute value $y_{i j}$ and the reference point $n_{j}$ of a scheme is calculated using the following formula:

$$
J_{i j}= \begin{cases}\left|\tilde{y}_{i j}-\tilde{n}_{j}\right| & i \in Z, j \in S_{1} \\ \sqrt{\frac{1}{2}\left[\left(y_{i j}^{L L}-n_{j}^{L L}\right)^{2}+\left(y_{i j}^{U L}-n_{j}^{U L}\right)^{2}\right]} & i \in Z, j \in S_{2} \\ \sqrt{\frac{1}{3}\left[\left(y_{i j}^{1}-n_{j}^{1}\right)^{2}+\left(y_{i j}^{2}-n_{j}^{2}\right)^{2}+\left(y_{i j}^{3}-n_{j}^{3}\right)^{2}\right]} & i \in Z, j \in S_{3}\end{cases}
$$

On this basis, the profit and loss decision matrix relative to the reference point $\boldsymbol{G}=\left[G\left(y_{i j}\right)\right]_{m \times n}$ can be established, where $G\left(y_{i j}\right)$ is the profit or loss value of the attribute value $y_{i j}$ relative to the reference point, and its calculation formula is provided below:

$G\left(y_{i j}\right)= \begin{cases}J_{i j} & y_{i j} \geq n_{j} \\ -J_{i j} & y_{i j}<n_{j}, \quad i \in Z, j \in T\end{cases}$

When $y_{i j} \geq n_{j}, G\left(y_{i j}\right)$ is referred to as the profit acquired by the attribute value $y_{i j}$ relative to the reference point $n_{j}$; when $y_{i j}<n_{j}, G\left(y_{i j}\right)$ is referred to as the loss generated by the attribute value $y_{i j}$ relative to the reference point $n_{j}$.

Considering the different attitudes that decisionmakers of warehousing centre locations have towards the risks of profit and loss as well as the uncertainty of individual schemes, the comprehensive prospect value for each scheme $C V\left(p_{i}\right)$ is calculated according to the cumulative prospect theory. The prospect value consists of the value function and decision weight function. The value function represents the subjective utility developed by the decision-maker of the warehousing centre location, according to the actual utility of individual schemes.This indicates the deviation of the value from the reference point i.e., the profit or loss. The decision weight function represents the subjective occurrence probability developed by the decision-maker of the warehousing centre location, according to the actual occurrence probability of individual schemes.

(1) Value function

According to the profit and loss decision matrix $\boldsymbol{G}=\left[G\left(y_{i j}\right)\right]_{m \times n}$, the value function matrix $\boldsymbol{Q}=\left[Q\left(y_{i j}\right)\right]_{m \times n}$ is established, where $Q\left(y_{i j}\right)$ is the evaluation value of each scheme for individual attributes. The formula for the value function $Q\left(y_{i j}\right)$ is provided below [23]:

$$
Q\left(y_{i j}\right)= \begin{cases}{\left[G\left(y_{i j}\right)\right]^{\alpha}} & y_{i j} \geq n_{j} \\ -\lambda\left[-G\left(y_{i j}\right)\right]^{\beta} & y_{i j}<n_{j}, \quad i \in Z, j \in T\end{cases}
$$

where, the parameters $\alpha$ and $\beta$ are the degree of concavity and convexity of the function $Q\left(y_{i j}\right)$, which reflects the declining sensitivity rate of the decision-maker to the profit and loss, $0<\alpha<1,0<\beta<1$. The parameter $\theta$ signifies the degree of the decision-maker's avoidance of loss, which 
represents the fact that the decision-maker's avoidance of loss is greater than his preference on the same decision. $\theta$ $>1$ expresses the characteristics of subjective utility in the loss area steeper than the profit area [24]. The coefficients of $\alpha, \beta, \theta$ are calculated using the calibrated result in Kahneman and Tversky's research from 1992, with $\alpha=\beta$ $=0.88, \theta=2.25$.

\section{(2) Attribute weight}

The weights of individual attributes are calculated using the analytic hierarchy process (AHP), according to the expert assignments to each attribute.The specific assignment criteria are provided in Tab. 1.

Table 1 Definitions of attribute assignment criteria

\begin{tabular}{|c|c|}
\hline Scale & Table 1 Definitions of attribute assignment criteria \\
\hline 1 & Two factors are of equal importance through comparison \\
\hline 3 & $\begin{array}{c}\text { One factor is moderately more important than the other } \\
\text { factor through comparison }\end{array}$ \\
\hline 5 & $\begin{array}{c}\text { One factor which is significantly more important than the } \\
\text { other factor through comparison }\end{array}$ \\
\hline 7 & $\begin{array}{c}\text { One factor which is strongly more important than the } \\
\text { other factor through comparison }\end{array}$ \\
\hline 9 & $\begin{array}{c}\text { One factor which is extremely important over the other } \\
\text { factor through comparison }\end{array}$ \\
\hline $2,4,6,8$ & The situation within every two adjacent scales \\
\hline
\end{tabular}

The attribute weight is calculated using the square root method to construct the judgment matrix:

$$
\boldsymbol{U}=\left(u_{i j}\right)_{p \times p}
$$

The maximum characteristic root $\lambda_{\max }$ of the judgment matrix $U$ and its consistency check are calculated using the following formula:

$$
\begin{aligned}
& \lambda_{\text {max }}=\frac{1}{p} \sum_{i=1}^{p} \frac{(A W)_{i}}{W_{i}} \\
& C I=\frac{\lambda_{\max }-p}{p-1} \\
& C R=\frac{C I}{R I}
\end{aligned}
$$

where, the average random consistency index $R I$ is obtained from the calculation result of the consistency check $C I$. Then the consistency ratio $C R$ is calculated, when the random consistency ratio $C R<0,10$. The judgment matrix is considered to exhibit satisfactory consistency, otherwise, it is adjusted until it exhibits satisfactory consistency.

(3) Decision weight function

The weight is assigned to the subjective judgment probability $\omega_{j}$ of the decision maker of the warehousing centre location by means of the probability weight function $W_{i j}$. The decision weight function is calculated using the following formula [25]:

$$
W_{i j}=\left\{\begin{array}{l}
\pi^{+}\left(\omega_{i j}\right)=\frac{\omega^{\gamma}}{\left[\omega^{\gamma}+(1-\omega)^{\gamma}\right]^{\frac{1}{\gamma}}} \\
\pi^{-}\left(\omega_{i j}\right)=\frac{\omega^{\delta}}{\left[\omega^{\delta}+(1-\omega)^{\delta}\right]^{\frac{1}{\delta}}}
\end{array}\right.
$$

where, $\pi^{+}\left(\omega_{i j}\right)$ is the decision weight when the decision maker acquires profit relative to the reference point, $\gamma$ is the parameter value when the decision-maker acquires a profit; $\pi^{-}\left(\omega_{i j}\right)$ is the decision weight when the decision-maker generates a loss relative to the reference point and $\delta$ is the parameter value when the decision-maker generates a loss. Kahneman and Tversky calibrated the coefficient values through research: $\gamma=0.61, \delta=0.69$.

Finally, the comprehensive prospect value is calculated using the following formula:

$$
C V\left(p_{i}\right)=\sum_{j=1}^{n} W_{i j} Q\left(y_{i j}\right), \quad i \in Z
$$

This demonstrates that a greater $C V\left(p_{i}\right)$ value results in the scheme $P_{i}$ being superior. Therefore, according to the size of $C V\left(p_{i}\right)$, the schemes can be ranked in a certain order.

In summary, the hybrid multi-attribute decisionmaking method based on the cumulative prospect theory is calculated using through these steps:

Step 1 According to Eqs. (1) to (11), normalise the reference point vector $E=\left(e_{1}, e_{2}, \cdots e_{n}\right)$, the decision matrix $\boldsymbol{D}=\left[d_{i j}\right]_{m \times n}$ to $N=\left(n_{1}, n_{2}, \cdots n_{n}\right)$, and $Y=\left[y_{i j}\right]_{m \times n}$ respectively.

Step 2 According to Eqs. (12) to (17), construct the profit and loss decision matrix $\boldsymbol{G}=\left[G\left(y_{i j}\right)\right]_{m \times n}$ relative to the reference point.

Step 3 According to Eqs. (18) to (23), construct the value function matrix and the decision weight matrix $W_{i j}$.

Step 4 According to Eq. (24), calculate the comprehensive prospect value $C V\left(p_{i}\right)$ for each scheme, and rank all schemes according to the size of $C V\left(p_{i}\right)$.

\section{EMPIRICAL ANALYSIS}

In this section, the SQ Logistics Company warehousing centre site selection problem is considered. In order to increase the economies of scale, improve the capacity of warehousing services, meet higher levels of logistics demands, and solicit new customers, the SQ Logistics Company intends to build a warehousing centre in Region $\mathrm{O}$. Five alternative locations are available for the warehousing centre $\left(P_{1}, P_{2}, P_{3}, P_{4}, P_{5}\right)$, and five attributes are considered here: area/scale $\left(P_{1}\right.$, unit: $\left.\mathrm{m}^{2}\right)$, rent level $\left(P_{2}\right.$, unit: $\mathrm{RMB} / \mathrm{m}^{2} /$ day), geographical location $\left(P_{3}\right)$, supporting infrastructure $\left(P_{4}\right)$, and natural environment $\left(P_{5}\right)$ of the warehousing centre. The geographical location includes the location of the warehousing centre relative to the customers, traffic accessibility, and surrounding public facilities. The supporting infrastructure includes the communications, energy, fire protection, hydropower systems and civil construction. The natural environment includes meteorological, geological, hydrological and topographical conditions. Among these alternatives, the expectation and the evaluation values, with respect to the attributes $P_{1}$ and $P_{2}$, are expressed in the form of interval 
numbers (the clear number can be treated as a special interval number), while with respect to the attributes $P_{3}, P_{4}$, and $P_{5}$, are expressed in the form of language phrases.

The SQ Logistics Company intends to build a largescale general logistics warehousing centre that integrates cargo transportation, warehousing, loading/unloading, and distribution, with an annual transport capacity of 3,000,000 tonnes. The decision-maker of the site selection calculates the expectation vector attribute to be $E=[(11000,13000),(0.4,1), M G, M, G]$ according to the available location information and the company's future expectation on the freight demand of the warehousing center, the decision matrix is provided in Tab. 2 .

Table 2 Decision matrix with multiple information attributes

\begin{tabular}{|c|c|c|c|c|c|}
\hline & $A_{1}$ & $A_{2}$ & $A_{3}$ & $A_{4}$ & $A_{5}$ \\
\hline$P_{1}$ & 10820 & $0.8-1.2$ & $\mathrm{G}$ & $\mathrm{M}$ & $\mathrm{MG}$ \\
\hline$P_{2}$ & 11940 & $0.6-1.3$ & $\mathrm{MG}$ & $\mathrm{G}$ & $\mathrm{M}$ \\
\hline$P_{3}$ & 13256 & $0.4-0.9$ & $\mathrm{M}$ & $\mathrm{MG}$ & $\mathrm{P}$ \\
\hline$P_{4}$ & 14650 & $1.2-4.5$ & $\mathrm{P}$ & $\mathrm{VG}$ & $\mathrm{MG}$ \\
\hline$P_{5}$ & 13700 & $0.2-0.7$ & $\mathrm{MP}$ & $\mathrm{G}$ & $\mathrm{M}$ \\
\hline
\end{tabular}

The SQ Logistics Company warehousing centre site selection problem is calculated according to the hybrid multi-attribute decision-making method, based on the cumulative prospect theory.

Step 1: Normalise the reference vector.

The five attributes are classified according to the characteristics of the decision attribute: $P_{1}, P_{3}, P_{4}$, and $P_{5}$ are benefit attributes, while $P_{2}$ is the cost attribute. The expectation vector for each attribute $E=[(11000,13000),(0.4,1), M G, M, G]$ is used as the reference point vector, and the reference point vector and decision matrix are normalised using Eqs. (1) to (11), depending on the specific attribute type:

(1) The reference vector is normalized to:

$\boldsymbol{N}=[(0.05,0.67),(0.81,0.95),(0.5,0.67,0.83),(0.33,0.5,0.67),(0.67,0.83,1)]$

(2) The decision matrix is normalized to:

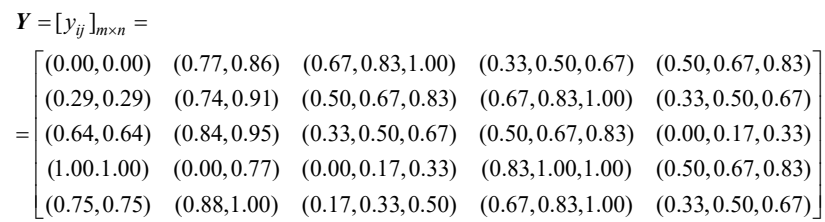

Step 2: Construct the profit and loss decision matrix

Firstly, according to Eqs. (12) to (15), the attribute value and reference point are compared, and the size relationships between the attribute value $y_{i j}$ and reference point $n_{j}$ are identified. Secondly, according to Eq. (16), the distance between the attribute value and referent point $J_{i j}$ is calculated. Finally, the profit and loss decision matrix is constructed relative to reference point $G=\left[G\left(y_{i j}\right)\right]_{m \times n}$.

$$
\boldsymbol{G}=\left[G\left(y_{i j}\right)\right]_{m \times n}=\left[\begin{array}{rrrrr}
-0.48 & -0.07 & 0.17 & 0.00 & -0.17 \\
-0.32 & -0.05 & 0.00 & 0.33 & -0.33 \\
0.42 & 0.03 & -0.17 & 0.17 & -0.67 \\
0.71 & -0.59 & -0.50 & -0.45 & -0.17 \\
0.50 & 0.06 & -0.33 & 0.33 & -0.33
\end{array}\right]
$$

Step 3: Construct the value function matrix and calculate the decision weight matrix.

Based on the profit and loss decision matrix, according to Eq. (18), the evaluation value of each scheme regarding individual attributes is calculated, and the value function matrix $\boldsymbol{Q}=\left[Q\left(y_{i j}\right)\right]_{m \times n}$ is constructed.

$\boldsymbol{Q}=\left[Q\left(y_{i j}\right)\right]_{m \times n}=\left[\begin{array}{rrrrr}-1.18 & -0.22 & 0.21 & 0.00 & -0.47 \\ -0.83 & -0.16 & 0.00 & 0.38 & -0.85 \\ 0.47 & 0.05 & -0.47 & 0.21 & -1.58 \\ 0.74 & -1.41 & -1.22 & -1.11 & -0.47 \\ 0.54 & 0.08 & -0.85 & 0.38 & -0.85\end{array}\right]$

Next, according to Eqs. (19) to (22), the attribute weight is calculated. The weight of each attribute is displayed in Tab. 3 .

Table 3 Weight of each attribute

\begin{tabular}{|c|c|c|c|c|c|c|}
\hline & $A_{1}$ & $A_{2}$ & $A_{3}$ & $A_{4}$ & $A_{5}$ & Weight \\
\hline$A_{1}$ & 1 & $1 / 3$ & $1 / 5$ & $1 / 5$ & 3 & 0.0805 \\
\hline$A_{2}$ & 3 & 1 & 2 & $1 / 4$ & 5 & 0.2292 \\
\hline$A_{3}$ & 5 & $1 / 2$ & 1 & 3 & 5 & 0.3162 \\
\hline$A_{4}$ & 5 & 4 & $1 / 3$ & 1 & 7 & 0.3304 \\
\hline$A_{5}$ & $1 / 3$ & $1 / 5$ & $1 / 5$ & $1 / 7$ & 1 & 0.0437 \\
\hline
\end{tabular}

Finally, according to Eq. (23), the decision weight matrix is calculated.

$$
W_{i j}=\left[\begin{array}{lllll}
0.1493 & 0.2787 & 0.3270 & 0.3344 & 0.1025 \\
0.1493 & 0.2787 & 0.3270 & 0.3344 & 0.1025 \\
0.1674 & 0.2851 & 0.3382 & 0.3344 & 0.1025 \\
0.1674 & 0.2787 & 0.3382 & 0.3474 & 0.1025 \\
0.1674 & 0.2851 & 0.3382 & 0.3344 & 0.1025
\end{array}\right]
$$

Step 4: According to Eq. (24), calculate the comprehensive prospect value for each scheme.

$$
C V\left(P_{i}\right)=\left[\begin{array}{l}
C V\left(P_{1}\right) \\
C V\left(P_{2}\right) \\
C V\left(P_{3}\right) \\
C V\left(P_{4}\right) \\
C V\left(P_{5}\right)
\end{array}\right]=\left[\begin{array}{l}
-0.2170 \\
-0.1286 \\
-0.1477 \\
-1.1155 \\
-0.1343
\end{array}\right]
$$

According to the comprehensive prospect value of each scheme, the schemes were ranked in the corresponding order: $P_{2} \succ P_{5} \succ P_{3} \succ P_{1} \succ P_{4}$.

\section{CONCLUSION}

With respect to the site selection problem of logistics enterprise warehousing centres, this paper has proposed a hybrid multi-attribute decision-making method, taking into 
account the decision-maker's expectations. The proposed method considers the decision-maker's dependence on references, different attitudes taken towards the profit and loss risks,subjective judgment of different attribute selection factors, as well as other psychological behaviour characteristics. The decision maker assigns subjective expectations to the warehousing centre location factors with different attributes, takes this as the reference point based on the cumulative prospect theory, and constructs the profit and loss decision matrix and attribute value matrix relative to the reference point. Finally, the decision-maker calculates the decision weight value according to the subjective weight of individual attributes, constructs the decision weight matrix and ranks the schemes according to their comprehensive prospect value. This, in turn, provides the decision-maker with a basis for decision-making. This paper applies the prospect theory in the proposed hybrid multi-attribute decision-making method, providing a referential concept and basis for the use of the prospect theory in the location decision of logistics enterprise warehousing centres. This method accurately processes multi-attribute information during the site selection of a logistics enterprise warehousing centre, and also fully demonstrates the decision-maker's psychological expectations with respect to factors with different attributes. It features a clear concept, and simple calculation process, and tends to be more operable and practical, thereby providing a new approach for location decisions of logistic enterprise warehousing centres.

\section{Acknowledgements}

This research was partially funded by the National Natural Science Foundation of China (71373060), the National Social Science Fund of China (14GL004), the Natural Science Foundation of Heilongjiang Province (G201404) and the Social Science Fund of Heilongjiang Province (13D011).

\section{REFERENCES}

[1] Hong, L. I. (2008). Research on Location Planning of the Warehouse and Distribution Center of Huada Logistics Company. Industrial Engineering \& Management, 13(1), 116-120. https://doi.org/10.3969/j.issn.1007-5429.2008.01.023

[2] Gong, D., Tang, M., \& Liu, S. (2017). Reconsidering Production Coordination: A Principal-Agent Theory Based Analysis. Advances in Production Engineering \& Management, 12(1), 51-61. https://doi.org/10.14743/apem2017.1.239

[3] Miao, X. D., Li, Y. H., \&Fan, C. J. (2004). A Discussion on Location Selection by Gravity Method. Communications Standardization, 10, 50-52. https://doi.org/10.3869/j.issn.1002-4786.2004.10.030

[4] Yang, M. S. \& Xia, L. I. (2007). Application of Improved Gravity Method in Location of Logistics Distribution Center. Logistics Technology, 26(6), 60-62. https://doi.org/10.3969/j.issn.1005-152X.2007.06.020

[5] Toregas, C., Swain, R., Revelle, C., et al. (1971). The Location of Emergency Service Facilities. Opns Res, 19(6), 1363-1373. https://doi.org/10.1287/opre.19.6.1363

[6] Guan, F. \& Zhang, Q. (2013). A Fuzzy Multi-Objective Logistics Distribution Center Location Model and Its Solution Algorithm. Chinese Journal of Management Science, 57-62. https://doi.org/10.16381/j.cnki.issn1003-207x.2013.s1.049

[7] Tang, M., Gong, D., Liu, S., et al. (2016). Applying multiphase particle swarm optimization to solve bulk cargo port scheduling problem. Advance in Production Engineering \& Management, 11(4), 299-310. https://doi.org/10.14743/apem2016.4.228

[8] Zhang, Q., Gao, L. Q., \& Hu, X. P. (2004). Heuristic algorithm for location-allocation problem in integrated distribution. Journal of Northeastern University, 25(7), 637640. https://doi.org/10.3321/j.issn:1005-3026.2004.07.007

[9] Shakya, S. \& Mccall, J. (2007). Optimization by Estimation of Distribution with DEUM Framework Based on Markov Random Fields. International Journal of Automation \& Computing, 4(3), 262-272. https://doi.org/10.1007/s11633-007-0262-6

[10] White, L. (2016). Theory of the Location of Industries. Economic Geography, 7(1), 106. https://doi.org/10.2307/140943

[11] Zhang, T. X. \& Fan, J. W. (2008). Research on Logistics Centre with Algorithms for Solving the Shortest Path Improvement Problems. Cd Technology, (11), 40.

[12] Lotfi, V., Stewart, T. J., \& Zionts, S. (1992). An aspirationlevel interactive model for multiple criteria decision making. Computers \& Operations Research, 19(7), 671-681. https://doi.org/10.1016/0305-0548(92)90036-5

[13] Wang, J. \& Zionts, S. (2006). The aspiration level interactive method (AIM) reconsidered: Robustness of solutions. European Journal of Operational Research, 175(2), 948958. https:// doi.org/10.1016/j.ejor.2005.06.039

[14] Yunaba, Y. B. (2004). Multiple criteria decision making with generalized DEA and an aspiration level method. European Journal of Operational Research, 158(3), 697-760. https://doi.org/10.1016/S0377-2217(03)00375-8

[15] Nowak. M. (2007). Aspiration level approach in stochastic MCDM problems. European Journal of Operational Research, 177(3), 1626-1640 https://doi.org/10.1016/j.ejor.2005.10.003

[16] Tversky, A. (1979). Prospect Theory: An Analysis of Decision under Risk. Econometrica, 47(2), 263-291. https://doi.org/10.2307/1914185

[17] Wang, J. Q., Sun, T., \& Chen, X. H. (2009). Multi-criteria fuzzy decision-making method based on prospect theory with incomplete information. Control \& Decision, 24(8), 1198-1202. https://doi.org/10.3321/j.issn:1001-0920.2009.08.015

[18] Gao, J. W. \& Liu, H. H. (2016). Intuitionistic Linguistic Risky Multiple Attribute Decision Making Method based on Cumulative Prospect Theory. Mathematics in Practice \& Theory, (23), 57-65.

[19] Bao, T. T., Xie, X. L., \& Meng, P. P. (2017). Intuitionistic fuzzy hybrid multi-criteria decision making based on prospect theory and evidential reasoning. Systems Engineering-Theory \& Practice, 32(2), 460-468. https://doi.org/10.12011/1000-6788(2017)02-0460-09

[20] Tversky, A. \& Kahneman, D. (1992). Advances in prospect theory: Cumulative representation of uncertainty. Journal of Risk \& Uncertainty, 5(4), 297-323. https://doi.org/10.1007/BF00122574

[21] Heath, C., Larrick, R. P., \& Wu, G. (1999). Goals as reference points. CognPsychol, 38(1), 79-109. https://doi.org/10.1006/cogp.1998.0708

[22] Ishibuchi, H. \& Tanaka, H. (1990). An aspiration-level interactive model for multiple criteria decision making. Computers \& Operations Research, 48(2), 219-225. https://doi.org/10.1016/0377-2217(90)90375-L

[23] Schmidt, U. \& Zank, H. (2008). Risk Aversion in Cumulative Prospect Theory. Management Science, 54(1), 208-216. https://doi.org/10.1287/mnsc. 1070.0762

[24] Avineri, E. (2006). The Effect of Reference Point on Stochastic Network Equilibrium. Transportation Science, 40(4), 409-420. https://doi.org/10.1287/trsc.1060.0158 
[25] Gonzalez, R. \& Wu, G. (1999). On the shape of the probability weighting function. Cognitive Psychology, 38(1), 129-166. https://doi.org/10.1006/cogp.1998.0710

\section{Contact information:}

Yonghong MA, Professor

School of Management and Economics, Harbin Engineering University,

No. 145, Nantong Road, Harbin 150000, China

E-mail: mayonghong0324@163.com

Xin SU, PhD Student

(Corresponding author)

School of Management and Economics, Harbin Engineering University,

No. 145, Nantong Road, Harbin 150000, China

E-mail: suxin0530@163.com

Yue ZHAO, PhD Student

School of Management and Economics, Northeast Forestry University,

No. 26, Hexing Road, Harbin 150040, China

E-mail: zhaoyue7319@126.com 